\title{
Carpal tunnel release in patients on coumadin
}

\author{
MSG Bell MD
}

$\mathrm{C}$ arpal tunnel release is a common procedure, and is not

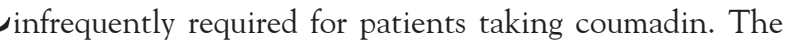
criteria for stopping coumadin in elective surgery are generally agreed upon (1). There are certain circumstances, however, in which it is inappropriate to stop the drug for three days before surgery, and in that group of patients, steps are taken to minimize the chances of postoperative bleeding.

The author has published a previous report using $\mathrm{CO}_{2}$ laser assistance for carpal tunnel surgery (2). Unfortunately, this is not a common device, and the use of simple electrosurgical cautery is preferred.

The author has devised an effective technique that is safe and efficacious.

Xylocaine with adrenaline is used for the anesthesia (3) because it helps with local hemostasis and allows one to more readily identify a vessel of any size or concern. Approximately $0.2 \mathrm{~mL}$ is deliberately placed deep to the volar carpal ligament.

The skin is incised with a number 15 blade into the subcutaneous tissue. Following this, all dissection is done with an Ellman Surgitron (Ellman International Inc, USA) with a tungsten wire tip, sequentially working down to the volar carpal ligament.

I have found that the best visualization for doing this with accuracy and safety is with using the CANICA PalmSpring carpal tunnel retractor.

Once the ligament is encountered, it can be incised distally with a number 15 blade because it is quite avascular.

A standard grooved director is passed beneath the ligament and run proximally about $2.5 \mathrm{~cm}$. This can be done without any discomfort because of the xylocaine with adrenaline block.

The cutting cautery is then used to divide the residual elements of the ligament superficial to the grooved director under complete control and safety, visualizing any potential small vessels that may not be effectively coagulated during the incision (Figure 1).

The author has not had a single episode of bleeding or hematoma formation in eight patients when using this technique, and

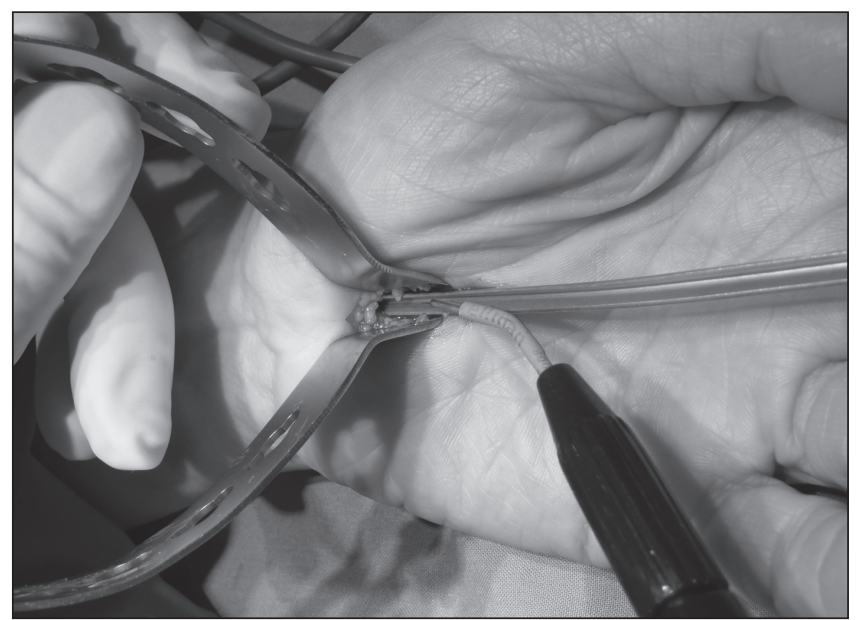

Figure 1) Using the CANICA PalmSpring carpal tunnel retractor to optimize visualization during carpal tunnel release surgery. The grooved director is beneath the volar carpal ligament

would recommend it as a reliable and safe procedure which should minimize this likelihood in patients on coumadin.

COMPETING INTEREST: Dr Bell is a shareholder of CANICA Design Inc.

\section{REFERENCES}

1. Kearon C, Hirsh J. Management of anticoagulation before and after elective surgery. $\mathrm{N}$ Engl J Med 1997;336:1506-11.

2. Bell MS, Ebrahimipour SS. The use of carbon dioxide laser in selected cases in patients on anticoagulant therapy. Can J Plast Surg 1999;7:237-9.

3. Pressman A, Doumit G, Rosaeg O, Bell MS. A double-blind randomized controlled trial showing the analgesic and anesthetic properties of lidocaine $\mathrm{E}$ to be equivalent to those of ropivicaine and bupivacaine in carpal tunnel release surgery. Can J Plast Surg 2005;13:173-6

\footnotetext{
The Ottawa Hospital, Ottawa, Ontario

Correspondence: Dr Michael Bell, 402 - 1919 Riverside Drive, Ottawa, Ontario K1H 1A2. Telephone 613-739-5424, fax 613-739-7168, e-mail msgbell@cyberus.ca
} 